\title{
Determination Minimum Distance between Ramp Entry and Exit on the Freeway Reviewed from the Road Safety Aspect
}

\author{
Deddy Santoso", Tri Tjahjono \\ Department of Civil Engineering, Faculty of Engineering, Universitas Indonesia, Indonesia
}

Received February 25, 2020; Revised May 20, 2020; Accepted May 30, 2020

Copyright $(2020$ by authors, all rights reserved. Authors agree that this article remains permanently open access under the terms of the Creative Commons Attribution License 4.0 International License

\begin{abstract}
This study was designed to discuss the minimum distance of access and exit in terms of road safety aspects. The safety aspect reviewed is looking for the relationship between the geometric aspects of the toll road to the level of accidents that occur. Accidents that occur are divided into three categories, namely; accidents that caused the death of the world, caused injuries and total accidents. The prediction model that will be made is a comparison of the three types of accidents with the geometric aspects of the toll road. Geometric data on toll roads, traffic volumes and accidents are taken from toll roads between the cities of Jagorawi, Jakarta-Tangerang, Padaleunyi, and Palikanci. The accident level model was developed using generalized linear modeling (GLM), and calibrated using statistical techniques. Some conclusions that can be drawn are: (1) The distance between the ramp entered and ramp out has a significant coefficient value for all prediction models; (2) The minimum road distance generated for the case of a 2 lanes in the death accident model is $9000 \mathrm{~m}$, for accidental injuries is $6000 \mathrm{~m}$ and the total accident is $5000 \mathrm{~m}$; (3) The minimum road distance generated for the case of a 3 lanes in the death accident model is $9000 \mathrm{~m}$, for accidental injuries is $5500 \mathrm{~m}$ and the total accident is $5000 \mathrm{~m}$; (4) The minimum road distance generated for the case of a 4 lanes in the death accident model is $6000 \mathrm{~m}$, for accidental injuries is $5000 \mathrm{~m}$ and the total accident is $4000 \mathrm{~m}$.
\end{abstract}

Keywords Accident Prediction Model, Generalized Linear Modeling, Geometric Toll Road, Minimum Ramp Distance, Negative Binomial

\section{Introduction}

The length of incoming and outgoing ramps on toll roads by application in field conditions is the distance between the toll gate and the other toll gate. However, in the current condition, toll road developers in Indonesia often make a distance between one toll gate segment and another based on the number of service factors required for travel numbers in the connected area. Ramp length conditions should be calculated based on existing regulatory standards to minimize the occurrence of node movements. When referring to domestic sources, the method of determining the length of incoming and outgoing ramps at MKJI no longer matches the current traffic characteristics in Indonesia. The difference between measured weaving capacity and modeling capacity ranges from $10 \%$ to $150 \%$ (Malkhamah, 2005). Different characteristic conditions in Indonesia today with previous years require a review regarding the length of incoming and outgoing ramps. For this reason, tools such as a simulation model are needed to provide a complete variation of traffic conditions which are interactions of various components such as geometric conditions and so on which can then be measured and calculated to determine the minimum length of incoming and outgoing ramps. The problem in developing the model is how the simulation model developed can mimic as closely as possible with the conditions on the ground. There needs to be a control parameter to determine whether the model being built is enough to represent field conditions or not. Determination of the minimum distance that is still developing today is based on the characteristics of Western countries, where behavior in traffic is by applicable regulations.

\section{Literature Review}

\section{Traffic Accident}

According to Government Regulation (PP) No. 43 of 
1993 concerning Road Infrastructure and Traffic, a traffic accident is an unexpected and unintentional road event involving a vehicle with or without other road users, resulting in human casualties or property loss.

Victims of traffic accidents can be:

a) Death victim is a victim who is confirmed to have died as a result of a traffic accident within a maximum period of 30 (thirty) days after the accident.

b) Severely injured victims are victims who due to their injuries suffer permanent disability or must be treated for more than 30 (thirty) days since the accident occurred.

c) Victims of minor injuries are victims who are not included in the definition of dead victims and victims of serious injuries.

\section{Negative Binomial}

The negative binomial distribution is a natural extension of the Poisson distribution, which takes into account the excessive variability that is sometimes found in accident prediction methods. This distribution is starting to be desirable for use in transportation research because it is used to help overcome problems that occur with Poisson modeling, especially variants that are possible to differ from the mean in negative binomial regression (Hadi, Aruldhas, J. J. A. Wattl, \& Chow, 1995). Both distributions relate to the Bernoulli sequence, where the negative binomial model can be considered as a more general distribution of calculated data compared to the Poisson model due to confounding factors that help to overcome the overdispersion problem that occurs in Poisson modeling (Allison, 1999). Beta coefficients in the model are estimated by the quasi-likelihood method (Knuiman, Council, \& Reinfurt, 1993). A maximum likelihood estimation is also an efficient way to estimate parameters in negative binomial regression. Regression models have the form:

$$
\log \lambda=\beta_{0}+\beta_{1} X_{i 1}+\ldots . .+\beta_{k} X_{i k}+\sigma \varepsilon_{i}
$$

Where the dependent variable $\mathrm{Y}$ is assumed to follow the Poisson distribution with the expected value of $\lambda_{i}$ conditional to $\varepsilon_{\mathrm{i}}$ (Allison, 1999). The expected value $\varepsilon_{\mathrm{i}}$ is assumed to follow the standard gamma distribution. Furthermore, the unconditional distribution $Y_{\mathrm{i}}$ follows the negative binomial distribution (Allison, 1999).

The negative binomial distribution is based on a negative binomial random variable where the number of successes is fixed and the number of random replications (Devore, 1991). The random variable of concern is $X=$ number of failures that precede success to $\mathrm{r}$. $\mathrm{X}$ has possible values of 0 , $1,2, \ldots$ The probability mass function for the negative binomial distribution can be written as:

$$
P(X=k)=\left(\begin{array}{l}
k-1 \\
r-1
\end{array}\right) p^{r}(1-p)^{k-r} \text { where } k=r, r+1, \ldots .
$$

For example, the sequence of free tests is carried out until all of them are successful; where $\mathrm{X}$ represents the total number of replications. To get $P(X=k)$, we can do it in the following way: From independent assumptions, each sequence has a probability $p^{r}(1-p)^{k-r}$. The last test was successful, and the remaining successful $r-1 \mathrm{~s}$ could be given to the remaining $k-1$ tests by $\left(\begin{array}{l}k-1 \\ r-1\end{array}\right)$ [1]. If the $\mathrm{r}$ event occurs at the $\mathrm{k}$, there will be exactly the $r-1$ event before the $n-1$ test and on the $\mathrm{k}$ it also occurs. ' $X$ ' is usually defined as the total number of replications in distribution, but sometimes it is defined as the total number of failures in distribution [1]. The way of writing the probability mass function allows a relationship between the binomial distribution and the negative binomial distribution. Both distributions consist of independent replay sequences.

In a negative binomial distribution, the mean does not have to be the same as the variant. The mean for negative binomial random variables is equal to:

$$
\mu=E(x)=\frac{r}{p}
$$

While the variants are the same as:

$$
\sigma^{2}=V(x)=\frac{r(1-p)}{p^{2}}
$$

\section{Method}

Mathematical modeling is a technique for creating quantifiable methods to predict the occurrence of certain events. An accident prediction model is an equation that states the frequency of accidents as a function of traffic flow and other road characteristics. Many issues arise related to the modeling and to the nature of the traffic accident itself. Many important issues are discussed in the following sections.

GLM (Generalized Linear Modeling) is the most direct method used to develop mathematical models. The choice of probability distribution in GLM is flexible for random components, which makes this model effective for traffic safety where the number of accidents and other variables follows the Poisson or negative binomial distribution and the other variables follow the normal distribution.

The researcher uses a negative binomial distribution because it assumes that the accident rate is a distribution of events that are rare, random and not negative. One drawback of Poisson Regression is overdispersion where the assumption of pure Poisson error structure can be seen as inadequate. The negative binomial model is often chosen to overcome this problem as an extension of the Poisson model. But often variants greater than average occur due in part to the exclusion of all relevant variables from the model (Knuiman, Council, \& Reinfurt, 1993). If the variant is greater than the average, this is called overdispersion.

The research variable consisted of two variables, the outcome variable, and the predictor variable. The outcome variable is the variable whose value will be predicted, 
while in this study the outcome variable is as follows:

- $\quad \mathrm{MD}=$ Number of deaths (people killed)

- $\quad \mathrm{LK}=$ Number of injuries (serious injuries and minor injuries)

- $\quad \mathrm{TK}=$ Total number of accidents

Predictor variables are causal variables that will affect the value of the outcome variable. Predictor variables in this study consisted of various factors including:

- $\quad$ SPACING = Distance between ramp entry and exit $(\mathrm{km})$

- $\quad$ RWID $=$ Lane width (m),

- MEDWID = Median width (m),

- MEDTYPE $=$ Median type,

- RSHLDTYPE = Outer and inner road shoulder, and

- $\quad$ NUMLANES $=$ The number of lanes on the toll road of the research location.

- $\quad \mathrm{AADT}=$ Daily average volume

The choice of location in this study is based on acceptance criteria. The location of this study was conducted on several toll roads on the island of Java, including Jagorawi Toll Road, Padalarang-Cileunyi Toll Road, Palikanci Toll Road, and Jakarta-Tanggerang Toll Road.

The primary data that researchers need in this study are the length of the ramp, the number of toll lanes, the width of the shoulder, the median width of the road, and the width of the toll road itself. Primary data was obtained using a direct survey on the toll road of the research location and using the help of the google-maps application in obtaining some research data. From Google Earth satellite imagery, researchers can measure the distance of the ramp on each related toll road section and can see other geometric aspects of the road. The first data collection was done by taking the geometric data of each toll road on the research object, namely along the Jagorawi, Palimanan-Kanci, Padelarang-Cileunyi, and Jakarta-Tangerang toll roads. Geometric data for toll roads taken follows cross-sections of toll roads that refer to cross-sections of expressways for toll roads on land-based sources (Bina Marga, 2009).

Furthermore, in the process of collecting accident data with the help of the IRSMS, first select the segment of each toll road on the object of research, namely the Jagorawi,
Palimanan-Kanci,

Padelarang-Cileunyi, and Jakarta-Tangerang toll roads. Accident data taken are accident data that are five years old from the range of 2014-2018, this is done to multiply sample data as compiler data for modeling using the R. program, accidents with serious injuries (LB) and accidents with fatalities (MD). For daily average vehicle traffic volume obtained from PT. Jasamarga, where the data obtained, can be in the form of the average daily traffic volume of vehicles at each toll road gate there is a research location.

After all the variable data needed in making the research model is then entered into the $\mathrm{R}$ program, then the related variable data is summarized to produce data in the form of mean, median, min, and max values for each of these variables. This is done to make it easier to make $\mathrm{R}$ models and also provide an overview of the spread of data on each of the related variables so that it can be displayed in the form of a graph of the spread of the variable data.

\section{Research Results}

The modeling is divided into several cases for toll roads consisting of 2 lanes, 3 lanes, and 4 lanes. This is to see also whether differences in the number of lanes can affect the level of accidents that occur. From the modeling produced by the R program it is known from all road geometric variables that the ramp length factor greatly influences the accident modeling, so that we can make a design recommendation on the distance between the incoming and outgoing ramps reviewed by road safety aspects where the factor is the number of victims died, many injuries and the magnitude of the total accident.

\section{Accident Prediction Model}

In making recommendations later, it will be taken into consideration in determining the geometric design of toll roads, especially in the case of Indonesia in determining the distance between incoming and outgoing ramps. It can be seen that the ramp distance factor (SPACING) is a very significant variable of all models, so we can summarize it into a predictor function modeling formula table that is the distance of the ramp to each type of accident into di below

Table 1. Summary of Accident Prediction Model

\begin{tabular}{|c|c|c|c|c|}
\hline \multirow{2}{*}{ Modeling } & \multicolumn{4}{|c|}{ Condition of Number of Toll Roads } \\
\hline & 2 Lanes & 3 Lanes & 4 Lanes & Lane Combined \\
\hline \multirow{2}{*}{ Fatality (MD) } & $e^{-1.462+(0.3206 * S P A C I N G)}$ & $e^{-2.135+(0.416 * S P A C I N G)}$ & $e^{-1.609+(0.476 * S P A C I N G)}$ & $e^{-1.538+(0.349 * S P A C I N G)}$ \\
\hline & $\varepsilon=37.8 \%$ & $\varepsilon=51.7 \%$ & $\varepsilon=61.07 \%$ & $\varepsilon=41.7 \%$ \\
\hline \multirow{2}{*}{$\begin{array}{l}\text { Total Injury } \\
\text { (LK) }\end{array}$} & $e^{-0.794+(0.378 * S P A C I N G)}$ & $e^{-1.275+(0.561 * S P A C I N G)}$ & $e^{-0.731+(0.471 * S P A C I N G)}$ & $e^{-0.750+(0.411 * S P A C I N G)}$ \\
\hline & $\varepsilon=45.96 \%$ & $\varepsilon=75.27 \%$ & $\varepsilon=60.27 \%$ & $\varepsilon=50.9 \%$ \\
\hline \multirow{2}{*}{$\begin{array}{l}\text { Total Crash } \\
\text { (TK) }\end{array}$} & $e^{-0.477+(0.383 * S P A C I N G)}$ & $e^{-1.037+(0.564 * S P A C I N G)}$ & $e^{-0.419+(0.489 * S P A C I N G)}$ & $e^{-0.459+(0.422 * S P A C I N G)}$ \\
\hline & $\varepsilon=46.67 \%$ & $\varepsilon=75.9 \%$ & $\varepsilon=63.19 \%$ & $\varepsilon=52.6 \%$ \\
\hline
\end{tabular}

*Information:

SPACING $=$ Distance between ramps $(\mathrm{km})$

$\varepsilon$ (Sensitivity) $=$ The addition of a large $\%$ of accidents to the increase in the value of SPACING by one unit $(\Delta \mathrm{X})$.

Source: Author Analysis, 2019 


\section{Accident Prediction Model}

After making a prediction model for each outcome variable for death victims (MD) and total accidents (TK), a density graph can be made for each model. The density graph is a graph that describes the density or density of a prediction model of the outcome variable. The density model that is formed from the three models is then made a prediction value that can display a prediction model graph using the $\mathrm{R}$ function. Graph modeling is made to be able to further understand the number of results predicted against the predictors that have been made.

The resulting density graph in Figure 1 will show the magnitude of the accident density for each existing ramp distance, the closer to zero and the stable density produced, the accidents that occur can be said to be non-existent so from these results we can set the minimum ramp length for each crash model which has been made. From the results of Figure 3 and the output $R$, it produced that for the combined lane case for accidental death the resulting density began to stabilize when entering a distance of 8,671 $\mathrm{km}$, while for accidents that cause injuries the resulting density began to stabilize when entering a distance of 5,968 $\mathrm{km}$ and for accidents of total density generated stable when entering a distance of 4,897 km. From these results, we can round off the minimum distance of the ramp in anticipation of safety so the minimum ramp distance for the accident death model is $9 \mathrm{~km}$, for injury accidents by $6 \mathrm{~km}$ and total accidents by $5 \mathrm{~km}$.

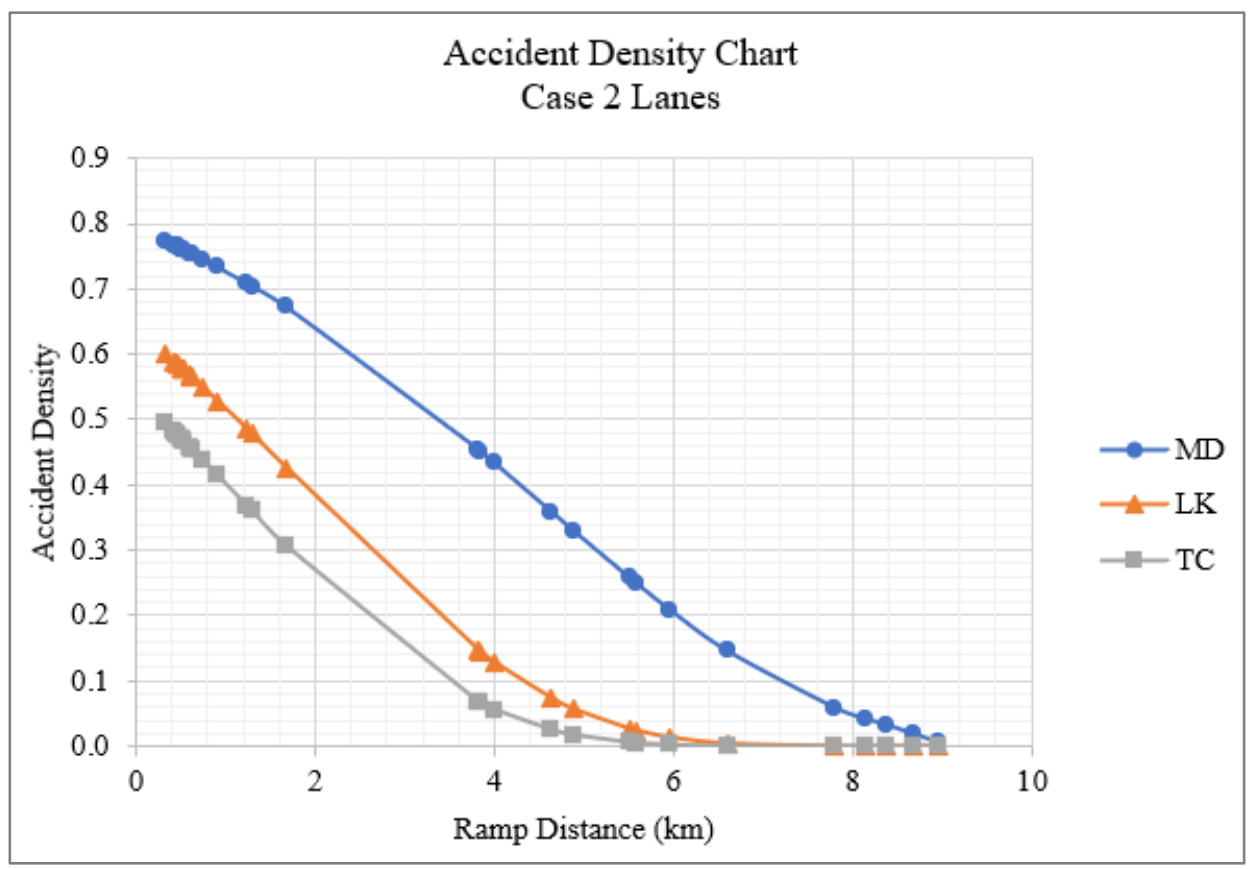

Figure 1. Accident Density Chart; Case 2 Lanes

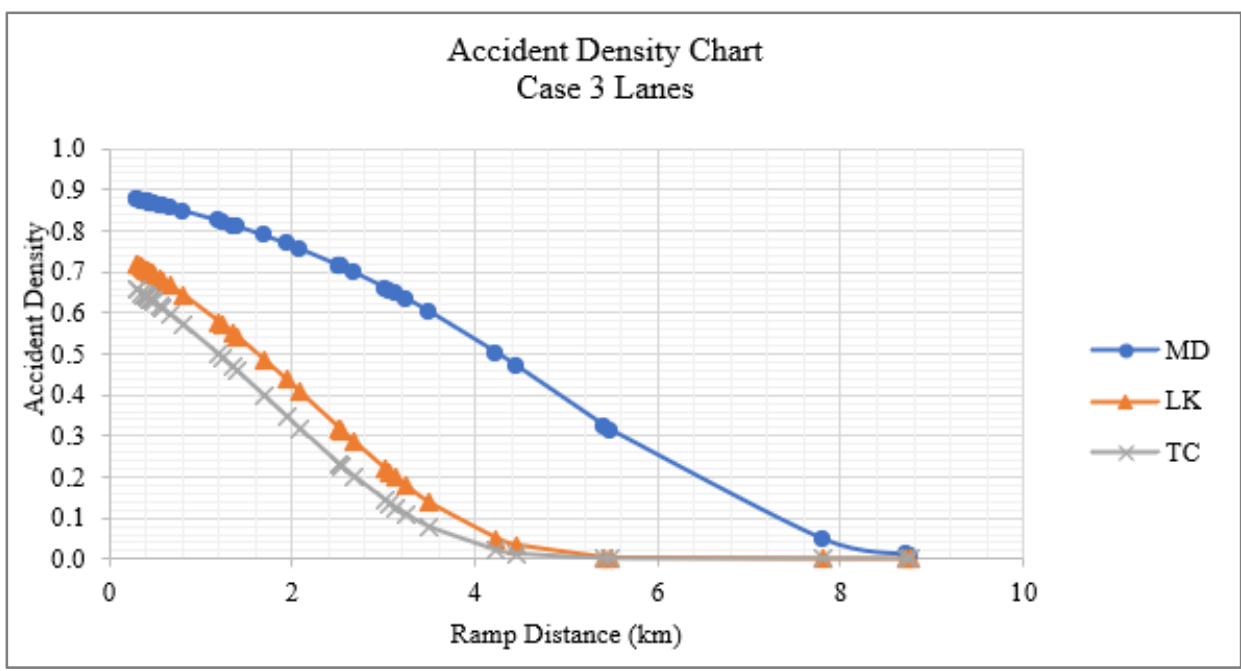

Figure 2. Accident Density Chart; Case 3 Lanes 
From the results of Figure 2 and output R, it is produced that for the combined lane case for accidental death the resulting density begins to stabilize when entering a distance of $8,720 \mathrm{~km}$, while for accidents which cause injury the resulting density starts to stabilize when entering a distance of $4,916 \mathrm{~km}$ and for an accident the total density generated stable when entering a distance of $4,529 \mathrm{~km}$. From these results, we can round the minimum distance of the ramp for the model of accident deaths by $9 \mathrm{~km}$, for accident injuries by $5.5 \mathrm{~km}$ and accidents totaling $5 \mathrm{~km}$.

From the results of Figure 3 and output R, it is produced that for the combined lane case for accidental death the resulting density begins to stabilize when entering a distance of $5.85 \mathrm{~km}$, while for accidents causing in jury the resulting density starts to stabilize when entering a distance of $4.54 \mathrm{~km}$ and for an accident the total density generated stable when entering a distance of $3,727 \mathrm{~km}$. From these results, we can round off the minimum distance of the ramp for the model of accident death by $6 \mathrm{~km}$, for injury accidents by $5 \mathrm{~km}$ and total accidents by $4 \mathrm{~km}$.

\section{Distance Ramp Recommendation}

After Based on the results of the density graph generated in each case of the accident model namely; cases for combined lanes, cases for 2 lanes, cases for 3 lanes, and cases for 4 lanes, it can be made a recommendation of minimum ramp distance between incoming ramps and out ramps as a result of the research output conducted at this time in Table 2.

Table 2. Summary of The Accident Model

\begin{tabular}{cc|c|c}
\hline \multirow{2}{*}{ Modeling } & \multicolumn{3}{c}{ Ramp Minimum Distance Length $(\mathrm{m})$} \\
\cline { 2 - 4 } & 2 Lane & 3 Lanes & 4 Lanes \\
\hline Fatality & 9000 & 9000 & 6000 \\
\hline Total Injury & 6000 & 5500 & 5000 \\
\hline Total Crash & 5000 & 5000 & 4000 \\
\hline Source
\end{tabular}

Source: Author Analysis, 2019

From the results of Table 2, at the minimum ramp, distance is produced on the condition of the toll road consisting of 4 lanes and then followed on the condition of
3 lanes and 2 lanes. This shows that in conditions of 4 lanes, accidents are less common compared to conditions of 3 lanes and 2 lanes. So that from the modeling it shows that the condition of the 2 lane accidents is more frequent, resulting in a longer ramp distance. If we assume the reality that there are 4 lane conditions, accidents are more common because of a condition commonly called weaving.

Weaving is the meeting of two or more traffic flows that run in the same direction along a path on the road without the help of traffic signs. This movement often occurs in one direction of the vehicle that moves from one lane to another, for example when the vehicle enters a highway from the driveway, then moves to another lane to take the exit from the road. This situation will lead to a point of conflict at the intersection (Transportation Research Board, 2000). Because weaving is related to the capacity of the road and the capacity of the road connected with the volume of the vehicle, further research needs to be added to variables outside the geometric variable, namely the volume of the vehicle.

Of all the variables that researchers estimate from the hypothesis, several variables can affect the accident rate besides the length of the ramp, namely the number of lanes and width of the road. Researchers get the results that this variable does not affect the accident rate both from the level of fatality (death), injury, and total accident. This can be implied that the two variables do not affect because the two variables cannot stand alone but must be followed by variables outside the geometric factor of the road. Both of these variables for further research can be combined with other factors in the form of average annual daily traffic volume (AADT). For the variable number of lanes, a new variable can be formed, namely the ratio of AADT volume per lane by dividing the AADT volume by the number of lanes in each toll road segment. Therefore the researcher divided the accident prediction model for all types of combined lanes into each increment of lanes starting from the prediction of types of accidents for two-lane, three-lane and four-lane toll road types.

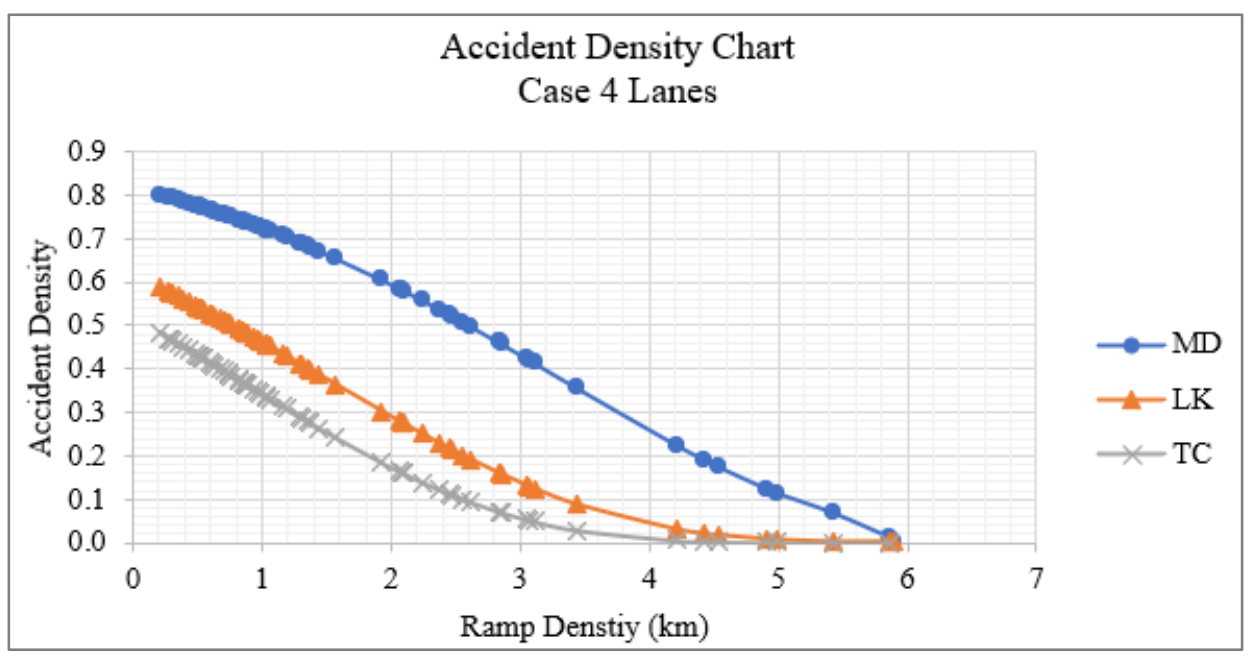

Figure 3. Accident Density Chart; Case 4 Lanes 


\section{Conclusions}

From the research that has been done in determining the minimum distance between incoming and outgoing ramps by reviewing road safety aspects in the form of accident rates in terms of death (MD), many injuries (LK) and overall victims (TK) can be concluded into several things including:

- Modeling to determine the minimum distance of the ramp is viewed from the aspect of road safety in the form of the death toll, many injuries and total accident victims. From the output of the modeling results and after seeing the significance it is produced that the ramp distance variable (SPACING) has the highest significance level of the variables for all existing models.

- The elasticity of the ramp distance variable to the accident rate has an effect of $37.8 \%-75.9 \%$ for each increase of one unit.

- The minimum distance of the ramp produced for the 2-lane toll road case in the accident model died by $9000 \mathrm{~m}$, for injury accidents by $6000 \mathrm{~m}$ and total accidents by $5000 \mathrm{~m}$.

- As for the condition of 3 ramps, the minimum distance of the resulting ramp for the combined lane case in the model of accident deaths is $9000 \mathrm{~m}$, for injury accidents by $5500 \mathrm{~m}$ and total accidents by $5000 \mathrm{~m}$.

- For the last case, the condition of 4 lane minimum distance of ramp that was produced for the combined lane case in the accident death model was $6000 \mathrm{~m}$, for wound accident was $5000 \mathrm{~m}$ and the total accident was $4000 \mathrm{~m}$.

\section{REFERENCES}

[1] Allison, P. D. (1999). Logistic Regression Using the SAS System: Theory and Application. Cary, NC: SAS Institute Inc.

[2] Bina Marga. (2009). Geometrik Jalan Bebas Hambatan Untuk Jalan Tol. Departemen Perkejaan Umum.

[3] Devore, J. L. (1991). Probability and Statistics for Engineering and the Sciences. Pasific Grove, California: Brooks/Cole Publishing Company.

[4] Hadi, M. J., Aruldhas, L. F., J.J.A. Wattl, \& Chow. (1995). Estimating safety effects of cross-section design of various hyghway types using negative binomial regression. Transport. Res Record.

[5] Knuiman, M. W., Council, F. M., \& Reinfurt, D. W. (1993). Association of Median Width and Highway Accident Rates. In Highway Research Record 1401. Washington D.C: Highway Research Board.

[6] Malkhamah, S. (2005). Pemodelan Kapasitas Bagian Jalinan Bundaran. Jurnal Media Teknik XXVII.

[7] Transportation Research Board. (2000). Highway Capacity Manual. 